\section{Venous compliance and clinical implications}

\author{
Paolo Zamboni, ${ }^{1}$ Valentina Tavoni, ${ }^{2}$ \\ Francesco Sisini, ${ }^{2}$ Massimo Pedriali, ${ }^{3}$ \\ Erika Rimondi, ${ }^{4}$ Mirko Tessari, ${ }^{1}$ \\ Erica Menegatti ${ }^{1}$
}

1The Department of Morphology, Surgery and Experimental Medicine and Vascular Diseases Center, University of Ferrara; Unit of Translational Surgery and Vascular Diseases Centre, Azienda Ospedaliera Universitaria, Ferrara; ${ }^{2}$ Section of Medical Physics, Department of Physics and Earth Sciences, University of Ferrara; ${ }^{3}$ Morbid Anatomy Service, Azienda Ospedaliera Universitaria, Ferrara; ${ }^{4}$ Department of Morphology, Surgery and Experimental Medicine and LTTA Centre, University of Ferrara, Italy

\section{Abstract \\ Compliance is a characteristic of every} deformable system. Compliance is very clear concept in physics and mechanics but in clinics, perhaps, is not the same. However, in veins compliance fits perfectly with the function of drainage of the venous system. Volumetric increase $(\mathrm{dV})$ of the content is correlated with pressure increase (dP) inside the vein according to the equation $C^{\prime}=d V / d P$. In humans $75 \%$ of the blood is located in the venous system, primarily because the molecular components of a vein media layer is significantly more compliant to that of arteries. This property is fundamental to understanding the change in blood volume in response to a change in posture. Measurements of venous compliance in clinical practice can be done by the means of ultrasound, as well as with the plethysmography. Ultrasound methods assimilate the cross sectional area to the volume of the vein, because it reflects the blood content. Changes in cross sectional area can be reliably measured in response to a change in posture, while pressure can be derived from the hydrostatic pressure changes. Venous compliance is of paramount importance also in pulsatile veins such as the inferior or superior vena cava and the jugular veins, where high resolution ultrasound may accurately derive the cross sectional area. Clinical implications of the mechanical properties of the venous wall are extensively discussed, including the need of dedicated venous stenting, which takes into account venous compliance as the main parameter of the venous function. In addition, venous compliance is the interpretative key for a better understanding of plethysmography curves, as well as of varicose veins and of their return to normal cross sectional area following ambulatory venous pressure reduction.

\section{The venous wall structure}

The structure, function and pathology of the venous system have received comparatively little attention when compared to similar studies on the arterial system. This neglect stems from a common tendency in medical thought: the presence of disease often dictates the need for fundamental studies of structure and function. The venous system always attracted little attention on behalf of researchers, with less number of studies respect to the arterial side of human blood circulation. ${ }^{1-3}$

All blood vessels have an inner layer, the intima, lined by endothelium with subjacent connective tissue; a middle layer, the media, composed of smooth muscle, elastic tissue and collagen embedded in a ground substance; and an outer layer, the adventitia, composed of elastic and fibrous tissue.

The endothelium is a monolayer of elongated epithelium - like cells that form the inner lining of the heart, arteries, capillaries, veins and lymphatics, the individual cells being oriented with the long axis along the direction of blood flow (Figure 1). Adjacent cells are connected by tight and gap junctions (Figure 2), the number and proportion of each varying in different parts of the vascular system and in different segments of vessel. An important function of the endothelium is the prevention of thrombosis, an almost inevitable consequence of significant breach in continuity of the otherwise smooth lining. The subjacent intimal tissue are highly thrombogenic, in consequence of the interaction between the endothelium, the Von Willebrand factor and the platelet, quickly initiating platelet adhesion and agglutination followed by fibrin deposition. ${ }^{4-6}$

The ability of blood vessel to accommodate or influence changes in blood flow and intraluminal pressure by contraction or relaxation rests largely with the smooth muscle component of their wall, moderated by connective tissue elements and a complex of vasoactive substances and the autonomic nervous system. ${ }^{3}$ At one time the smooth muscle was thought to be restricted to the media of vessels but with the advent of electron microscopy and other technological advances, such as immunohisto-
Correspondence: Paolo Zamboni, Unit of Translational Surgery and Vascular Diseases Centre, Azienda Ospedaliera Universitaria di Ferrara, via Aldo Moro 8, 44124 Loc. Cona, Ferrara, Italy.

Tel.: +39.0532237694 - Fax: +39.0532239788.

E-mail: paolozamboni@icloud.com

Key words: Veins; mechanical wall properties.

Received for publication: 21 February 2018.

Revision received: 13 April 2018.

Accepted for publication: 16 April 2018.

This work is licensed under a Creative Commons Attribution 4.0 License (by-nc 4.0).

(C) Copyright P. Zamboni, et al., 2018

Licensee PAGEPress, Italy

Veins and Lymphatics 2018; 7:7367

doi:10.4081/vl.2018.7367

chemistry, it was established that the transitional or myointimal cells, a prominent component of the intima in normal adult blood vessels and also of arteriosclerotic lesions, are smooth muscle cells. ${ }^{1-3}$ The individual smooth muscle cell is spindle shaped and surrounded by a closely applied basement membrane; it contains thick myosin and thin actin filaments imparting contractile properties. The cytoplasm also contains non-contractile intermediate filaments of vimentin and desmin type as part of the cytoskeleton. The dense bodies scattered throughout the sarcoplasm are analogous to the $\mathrm{Z}$ lines of skeletal muscle, acting as zones of attachment for contractile filaments, while the dense bands on the internal aspect of the plasma membrane are the anchoring sites for the contractile filaments. In addition, glycoproteins such as fibronectin act as transmitters of contractile forces from smooth muscle cells to the investing stroma of collagen and elastic tissue. Smooth muscle, in contrast to skeletal or cardiac muscle, will replicate and proliferate under appropriate stimuli as seen for example in the repair processes, in response to inflammation, in altered hemodynamic conditions such as hypertension and in atherosclerotic lesions.

Collagen and elastic tissue, the main fibrous proteins, are embedded in a complex ground substance of proteoglycans (acid mucopolysaccarides) and glycoproteins such as fibronectin, and lamina, the basement membrane glycoprotein. Of the eleven types of collagen described, types I and III of so called interstitial collagens are the major fibrous proteins of the walls of larger blood vessels; they are produced mainly by the fibroblasts of the adventitia but also by smooth muscle cells of the 
media These collagens provide the tensile strength of the vessel wall, putting a constraint on its distensibility, Types IV, V and VI collagens have also been isolated from vessel walls, the first two in particular association with the basement membranes of the endothelium and smooth muscle cells; type IV has been found in both intima and media. The proportion of collagen fibers is different respect to the arterial wall, and tell us how the mechanical properties between the two vessels category are so different. The reticulin identified by older histological techniques that demonstrate argyrophilia is now thought to consist of fine type III collagen fibres coated with proteoglycans and glycoproteins. Elastin is another prominent component of the vessel walls, evidenced by appropriate staining methods, where is concentrated to form the fenestrated lamella (internal elastic membrane or lamina).

The elasticity inherent in all blood vessels is not determined only by elastic tissue, as the name of this tissue would seem to imply, but is a synergistic function of contractile smooth muscle with its associated elastic tissue and matrix (Figures 1 and 2). Collagen, is the stiffer component of the venous wall, and the tensile element that serves to prevent over-distension of vessels.

Large veins possess a medial layer composed of bundles of smooth muscle cells embedded in connective tissues (Figure 2). The content of connective tissue exceeds that of the smooth cells. In some of the large veins, like the caval veins, the adventitia is thick and also contains an abundance of smooth muscle cells, usually with a longitudinal orientation. By contrast, the intima is thin in these large veins. The muscular nature of the media is more evident in medium-sized veins but collagen and elastin fibers are prominent between the smooth muscle cells. The adventitia is composed mainly of collagen, again usually oriented in longitudinal fashion, and it appears to be the thickest layer of the wall. In the adventitia layer are visible the vena venarum. The intima is relatively inconspicuous.

In venules, the layer of smooth muscle cells is discontinuous, this discontinuity being particularly evident in the post capillary venules. There is a gradual transition of the architecture of capillaries toward venules containing a layer of smooth muscle cells. The collecting veins, of diameter from 30-50 $\mu \mathrm{m}$, are the first ones that show smooth muscle cells underneath the layer of embedded cells. These smooth muscle cells gradually increase in number with concomitant increase in size of the venules and, eventually, from a continuous layers. Somewhat larger collecting veins, with a diameter of approximately $200 \mu \mathrm{m}$, have a true media with focal multilayering of smooth muscle cells. The efficient functioning of the venous system depends upon the competence of valves. This thin endothelium - lined structures are so constructed as to support the venous return to the heart against action of gravity. Venous valves occur in many veins, both small and large, that conduct blood flow against the gravity. They prevent the backflow of blood from the heart. There are papers describing the anatomy of valve system of different anatomical district's veins, correlating it with functions and with venous disorders. ${ }^{7-9}$ The valves are slender, semilunar, pocketlike flaps formed by local folding of the

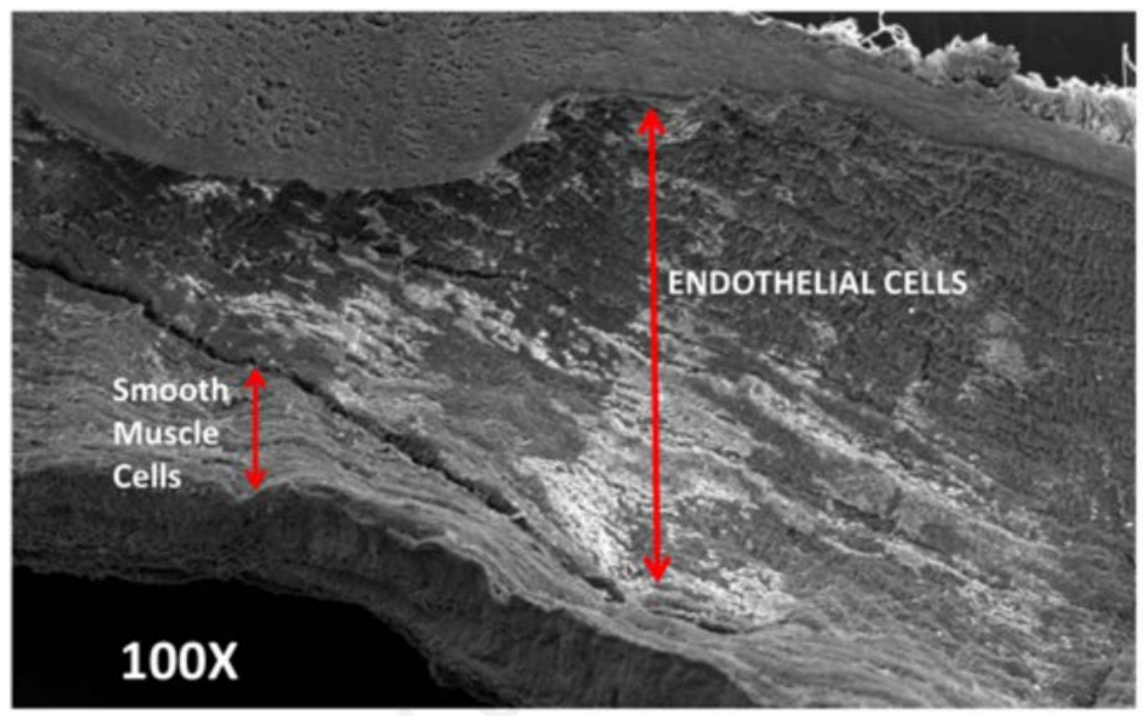

Figure 1. Standard scanning electronic microscopy of a human vein $(100 x) .^{40}$ The monolayer of the endothelial cells oriented along the flow axis is visible, together with the muscular component of the media layer.

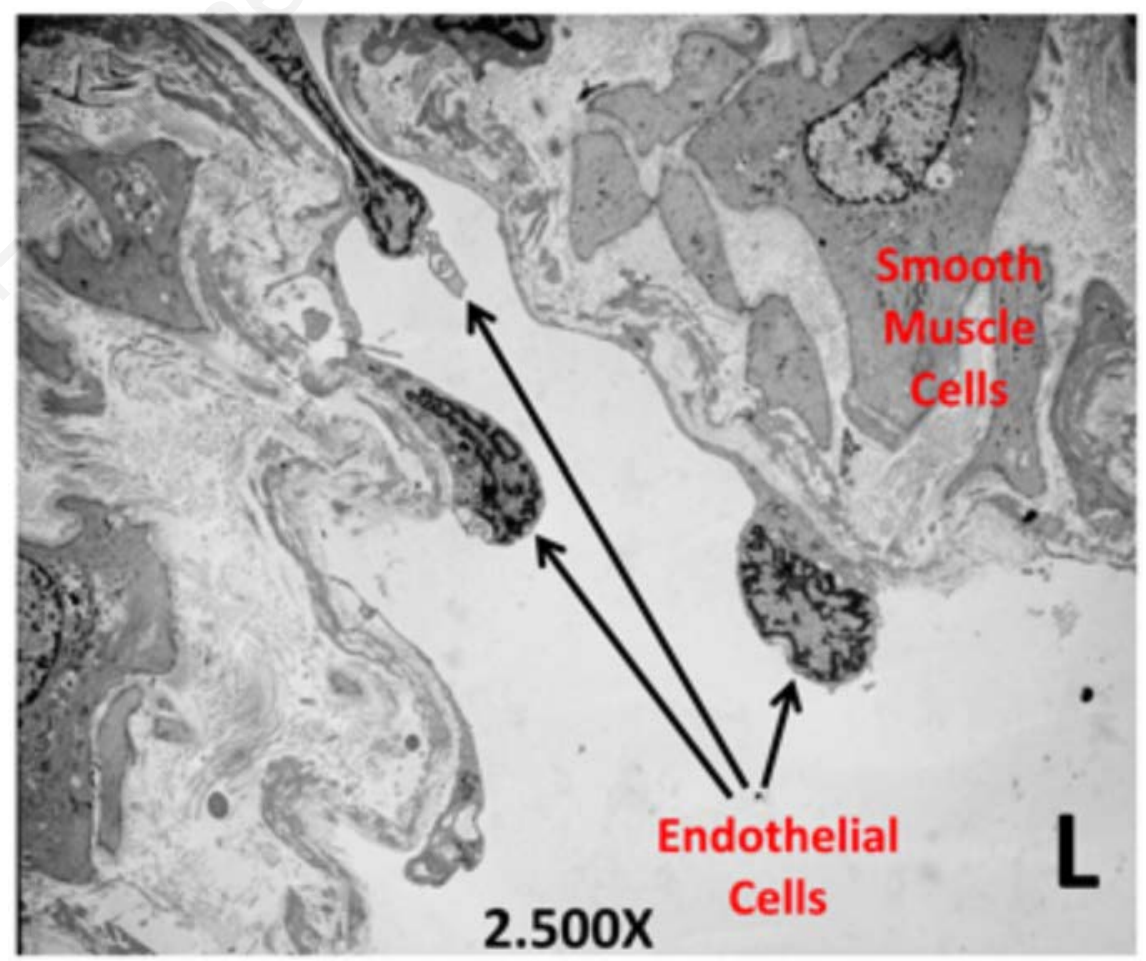

Figure 2. Transmission electronic microscopy 2500x showing the endothelial cells (black arrows) and the media layer with smooth muscle cells. Endothelial cells are separated by tight and gap junctions. $\mathrm{L}=$ lumen 
intima (Figure 3). ${ }^{7}$ Each valve is usually composed of two leaflets positioned opposite each other, with their free edges directed toward the heart. When blood passes throughout the lumen between the leaflets, they flatten out against the wall of the vein. When blood begins to regurgitate the pocket fills up, causing contact of the two leaflets and resulting in closing up of the vein's lumen (Figure 3). Venous valves are not found in cerebral veins, the superior vena cava, pulmonary veins, umbilical veins, or veins of viscera and bone marrow.

\section{The concept of venous compli- ance and the philosophy of venous function}

The histology described above is closely linked with the mechanical wall properties of the veins, and particularly with both elasticity and compliance. Compliance (C') is a characteristic of every deformable system. Compliance is very clear concept in physics and mechanics but in clinics is not often the same. However, in veins fits perfectly with the function of drainage of the venous system. The volumetric increase $(\mathrm{dV})$ of the content is correlated with pressure increase $(\mathrm{dP})$ inside the vein (the equation is $\left.C^{\prime}=\mathrm{dV} / \mathrm{dP}\right) .^{5-15}$ The components of the media layer of veins, described above, permit to the venous system to achieve high compliance respect to artery. Within the human body $75 \%$ of blood circulates in the venous system, because of greater compliance of veins respect the arteries. ${ }^{14}$

The venous system has higher compliance respect to the artery; it can receive a significant volume of blood with a small increase in pressure (Figure 4).

This capability to receive fluid in the conduit and to maintain the gradient of energy over time is expressed in physics as the compliance of the system. Basically, it depends from 3 main variables: i) the mechanical wall properties (elasticity/rigidity). The mechanical behaviour of material subjected to tension is described by Hooke's law $(\mathrm{F}=\mathrm{E} . \mathrm{dL})$, which states that every material subjected to a force tends to develop a reactive force (F) proportional to the elongation produced $(\mathrm{dL})$, in a linear ratio through a constant (E) (the Young modulus) which is characteristic of any material and represents the slope of the line $(\mathrm{E}=\mathrm{dL} / \mathrm{F}) .{ }^{16}$ Biological materials, however, do not obey this law and demonstrate a ratio between applied force (or developed force) and produced elongation that is not a straight line. The slope of the curve varies from point to point in proportion with the length and therefore is not a constant like the Young modulus; ii) the length of the vein, as above mentioned, and the cross sectional area (CSA) of the vessel; iii) the degree of filling of the vein. In Figure 5 it is well apparent the different behavior of the venous pressure when the vein is filled and distended by the blood respect to the empty vein (Figure 5). ${ }^{11-13}$

During the filling phase there is a sig- nificant increase in diameter of the vein with little change in pressure, ${ }^{11-13}$ in which the vein wall is not distended by the increase in blood volume. In other words, during this first phase the pressure/volume relationship is not linear (Figure 5). Instead, during the distension phase following the filling phase, further increases in volume are proportionally reflected by pressure increases, so that linearity of the volume/

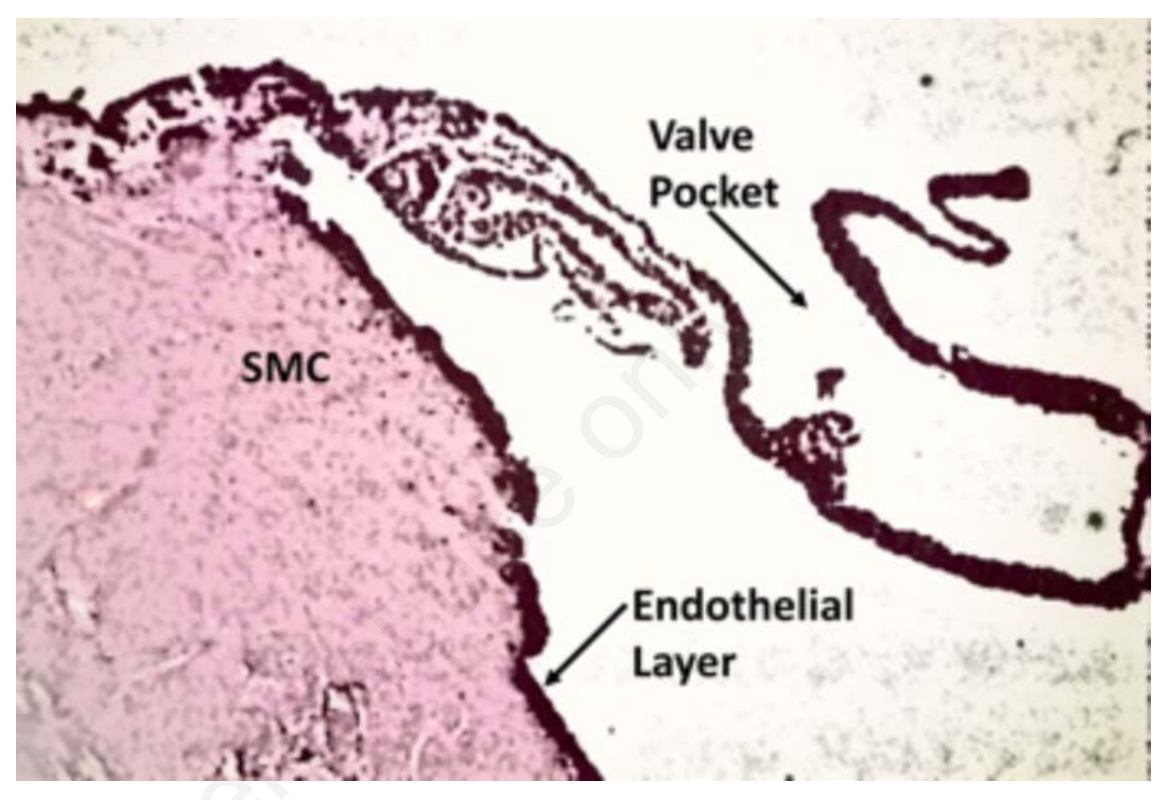

Figure 3. Light microscopy; Hematoxilin-Eosin. Venous valve with the pocket and the endothelial monolayer well apparent.

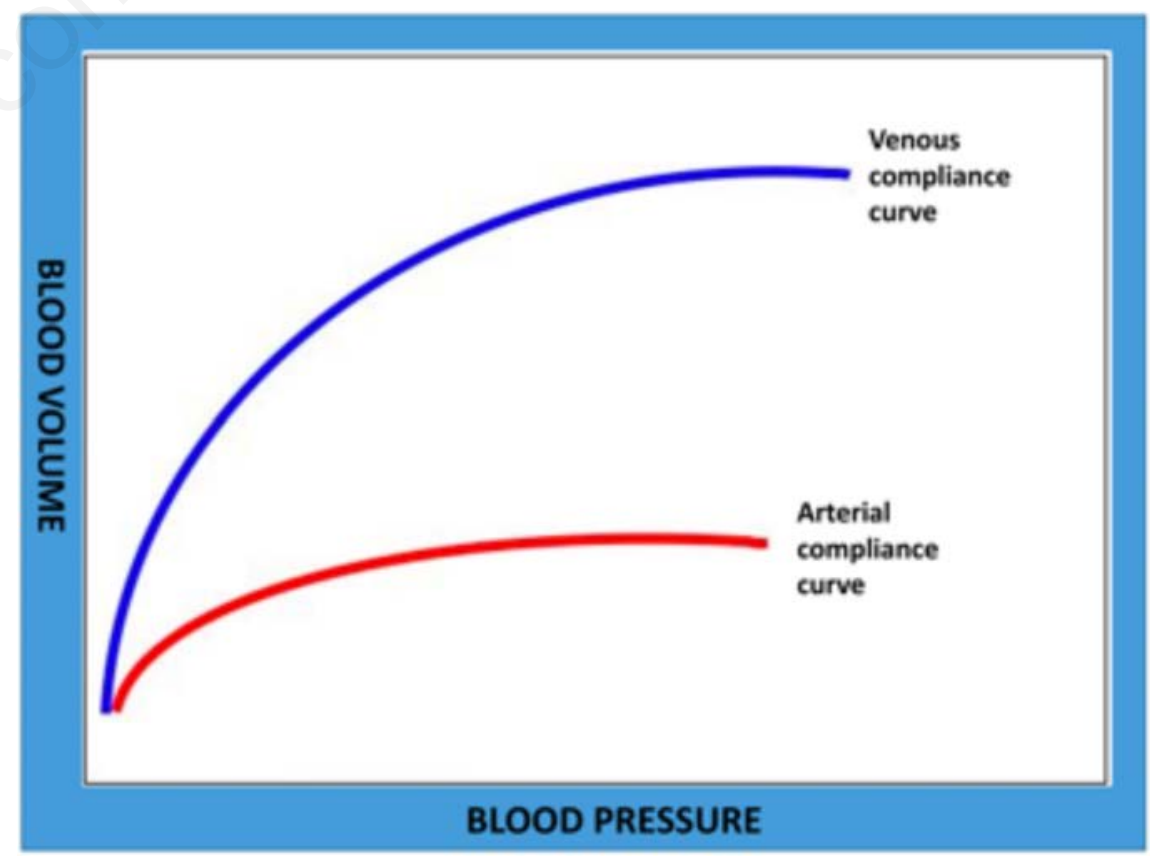

Figure 4. Given a change in pressure DP, the corresponding change in veins volume will be greater by that in arteries. This is because veins have a greater compliance than arteries. 
pressure relationship in veins can be demonstrated starting from pressure values around $20 \mathrm{mmHg} .{ }^{17}$ After completion of the filling phase, the vein diameter/cross sectional area is related to vein volume (provided that vessel length is constant). This may explain the finding of a linear pressure/diameter relationship in the filled veins (Figure 6). ${ }^{13,17}$ The shape of the compliance curve is determined, therefore, by the physical characteristics of the material involved $^{18-20}$ in the system, as well as by the volumetric extension of the system and its geometric configuration. The actual value of compliance is, instead, correlated, as we mentioned, with the filling volume of the system. ${ }^{14}$ In a hydrostatic system, with the fluid in stasis, both the volume and the pressure components are constant but in a hydrodynamic system, with the fluid in motion, the degree of filling in the system is influenced not only by the initial volume but also by the relationship between input rate and output rate.

\section{Venous compliance and postural changes}

The venous system needs of high compliance in order to respond to the physiological postural changes, which determine big variations of blood volume distribution. The hydrostatic pressure of gravity is the major regulator of the volume content of the vein. In the sub-diaphragmatic veins there are significant changes in volume according to the posture (Figure 7). In supine position the hydrostatic pressure is equalized within the venous system and the blood is equally redistributed in the upper and lower veins similarly to what happens in communicating vessels. But when the subject is in standing, due to the gravitational gradient, approximately $70 \%$ of the overall blood content in the human being is located below the diaphragmatic line. ${ }^{21-23}$ Venous compliance of the lower extremity permits to increase the CSA in order to accommodate the redistribution of blood below the diaphragmatic line (Figure 6). By contrast, in the neck veins like the internal jugular vein (IJV), in upright posture the hydrostatic pressure (HP) is negative, around -30 $\mathrm{mmHg}$, whereas in supine posture it ranges +5-7 mmHg. ${ }^{24-26}$ Passing progressively from supine to upright the hydrostatic pressure becomes negative because the IJV is placed above the heart. This means that the pressure external to the vein (atmospheric pressure $=\mathrm{AP}$ ) becomes prevalent, and squeeze the IJV which becomes smaller. In Figure 8 the progressive reduction of the
CSA of the IJV in normal subjects is given, showing the dramatic reduction passing from supine to upright. ${ }^{26}$ The variation in CSA expresses the volume variation respect to the variation of the hydrostatic pressure. The big difference of CSA in the two postural conditions expresses the excellent compliance of normal IJV. The measurements of CSA are consistent with correspondent volume changes measured by the means of plethysmography and of duplex scanning flow assessment. ${ }^{31-33}$

\section{Venous compliance and pulsatile veins}

In Figure 8 the big difference related to the change in posture in the CSA of the IJV is well apparent. The same happens in all the venous segments of the body when the hydrostatic gravitational gradient changes. In some veins, such as the superior vena cava system and the proximal segment of the inferior vena cava, the modality of car-

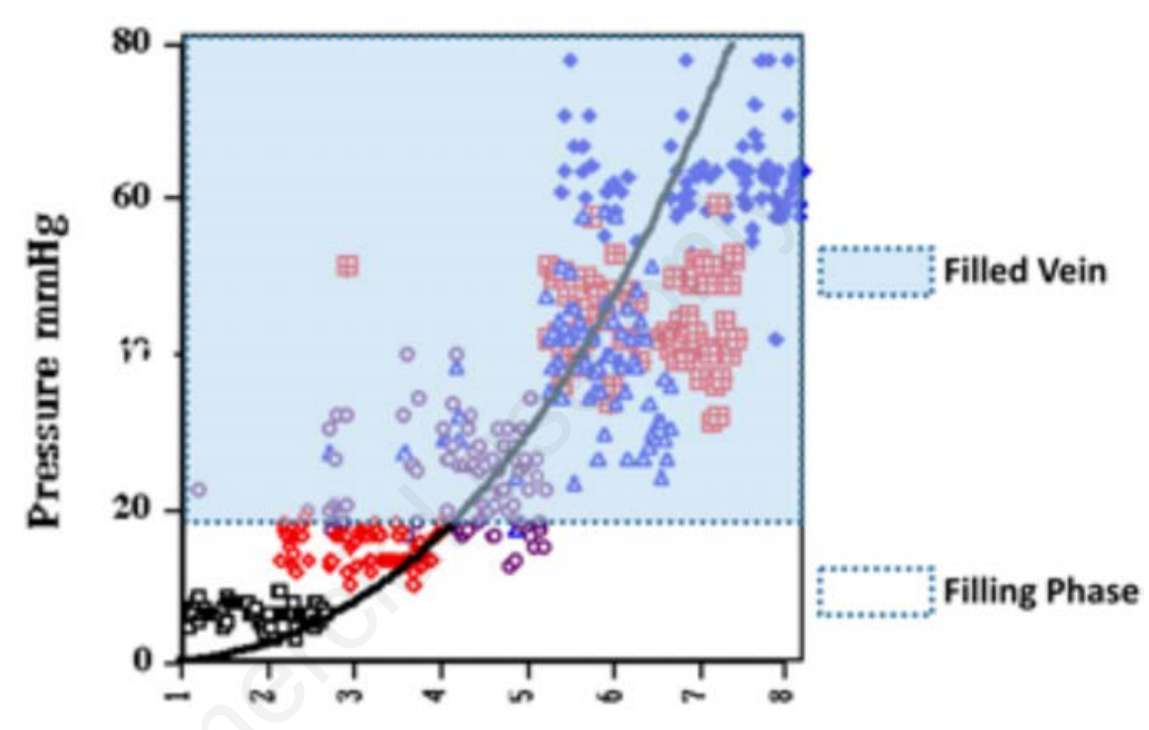

\section{Diameter mm}

Figure 5. During the filling phase (blue area) there is a significant increase in diameter of the vein with little change in pressure. When the blood volume distends the vein wall pressure and diameter are linearly related (above the blue area).

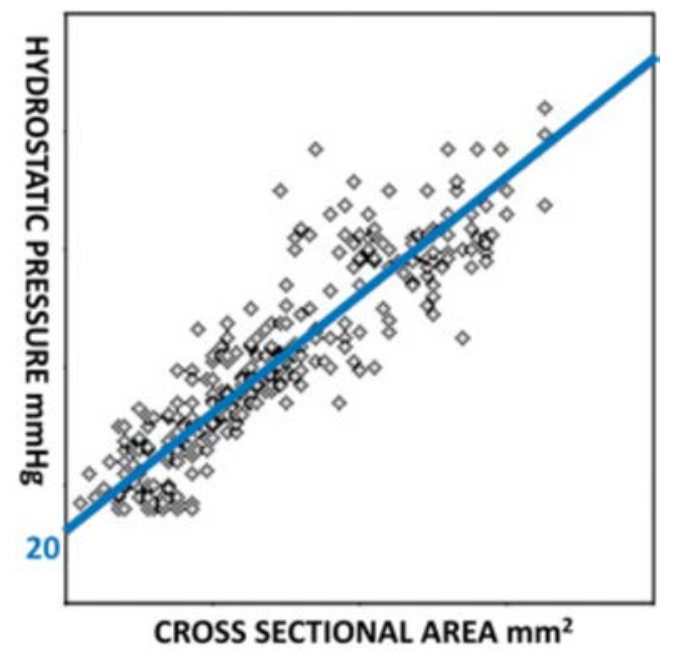

Figure 6. By changing posture, there is a redistribution of the blood volume in the venous system. If the veins are filled, the enlargement of the cross sectional area is linearly related to the increase of hydrostatic pressure. 
diac filling tends to further complicate the picture. Also in other area the close anatomical relationship between arteries and veins determines the transmission of pulsatility to the vein with further rhythmic modification of the venous compliance.

The jugular vein is a pulsatile vessel, and the pulsatility of the vein is visible with the naked eye at the level of the neck. The phenomenon is defined jugular venous pulse (JVP). It is the consequence of the transmission along the veins of the atrial pressure generated by the cardiac pump in the veins of the upper part of the body. ${ }^{34-38}$ Some authors compare the jugular pulsation to a barometer inserted into the atrium that measures the pressure variations in the cardiac atrium. The typical jugular venous pulse is characterized by a sequence of five waves, three positive (a, c, v) and two negative ( $\mathrm{x}$ and $\mathrm{y}$ ). ${ }^{34-38}$ When the atrium begins the contraction, signaled by the $\mathrm{p}$ wave of the ECG, there corresponds to the positive and higher a wave in the JVP (Figure 9). The negative peak $\mathrm{x}$ is the consequence of the lowering of the cardiac septum when the ventricles begin the contraction. Such negative wave is interrupted by a little positive wave $\mathrm{c}$, which corresponds to the closure of the tricuspid valve. The ventricle contraction generates a subsequent positive wave visible in the JVP and known as $\mathrm{V}$ wave. The latter is immediately followed by the descend $y$, generated by the opening of the tricuspid valve. The five waves phenomenon is repeated along each cardiac cycle.

Quite recently it has been developed a system to assess the JVP from a high resolution B-mode clip synchronized with ECG. ${ }^{36,37}$ From the clip it is possible to assess something like 30 different CSA of the vein for each of the cardiac cycle. The variations of the area correspond to the JVP and in fact the ultrasonic JVP nicely reproduces the waves sequence above described, permitting also from proper calculations to assess haemodynamic parameters such as flow velocity, flow rate, gradient of pressure and venous compliance. The modifications of the CSA are around $30 \%$ of the initial IJV CSA.

This is a quite direct example where the compliance concept can be used to obtain information from a physical/physiological system. In fact, from the Moens-Korteweg equation we have that the compliance per unit length is given by: ${ }^{30}$

$$
\mathrm{C}^{\prime}=\frac{\operatorname{CSA}_{\mathrm{x}}}{\rho \mathrm{c}^{2}}
$$

where CSAx is the CSA measured at the time correspondent to the $\mathrm{x}$ descent, $\mathrm{r}$ is the blood density and $\mathrm{c}$ is the velocity of the pulse wave transmitted from the heart toward the neck. ${ }^{30}$ The compliance C' is related to the blood pressure gradient by:

$$
\frac{\partial \mathrm{p}}{\partial \mathrm{z}}=\frac{1}{\mathrm{cC} \prime} \frac{\partial \mathrm{CSA}}{\partial \mathrm{t}}
$$

so that $\mathrm{c}$ and C' together can be used to calculate the pressure gradient inside the IJV. Since C' can be calculated by reversing Eq. 1 , the ability to calculate the pulse wave velocity c became the key to calculate blood pressure and consequently blood velocity

\section{Clinical implication of venous compliance}

The most important implication of the physiologic behavior of veins in terms of

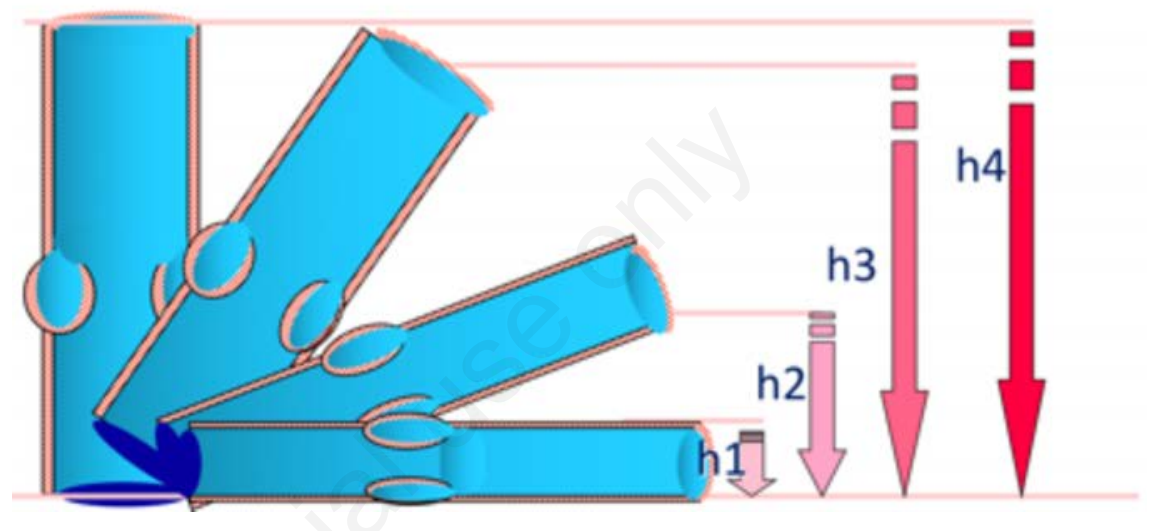

Figure 7. Change in cross sectional area and volume of the veins of the lower extremity passing from supine to standing posture. In posture, the hydrostatic pressure is very low (H4) and the veins are small because blood is distributed in the entire body. By increasing the hydrostatic pressure, with the subject respectively in 2 sitting and standing positions $(\mathrm{H} 3, \mathrm{H} 2, \mathrm{H} 1)$, venous compliance permits to accommodate more blood volume and the cross sectional area is proportionally enlarged.

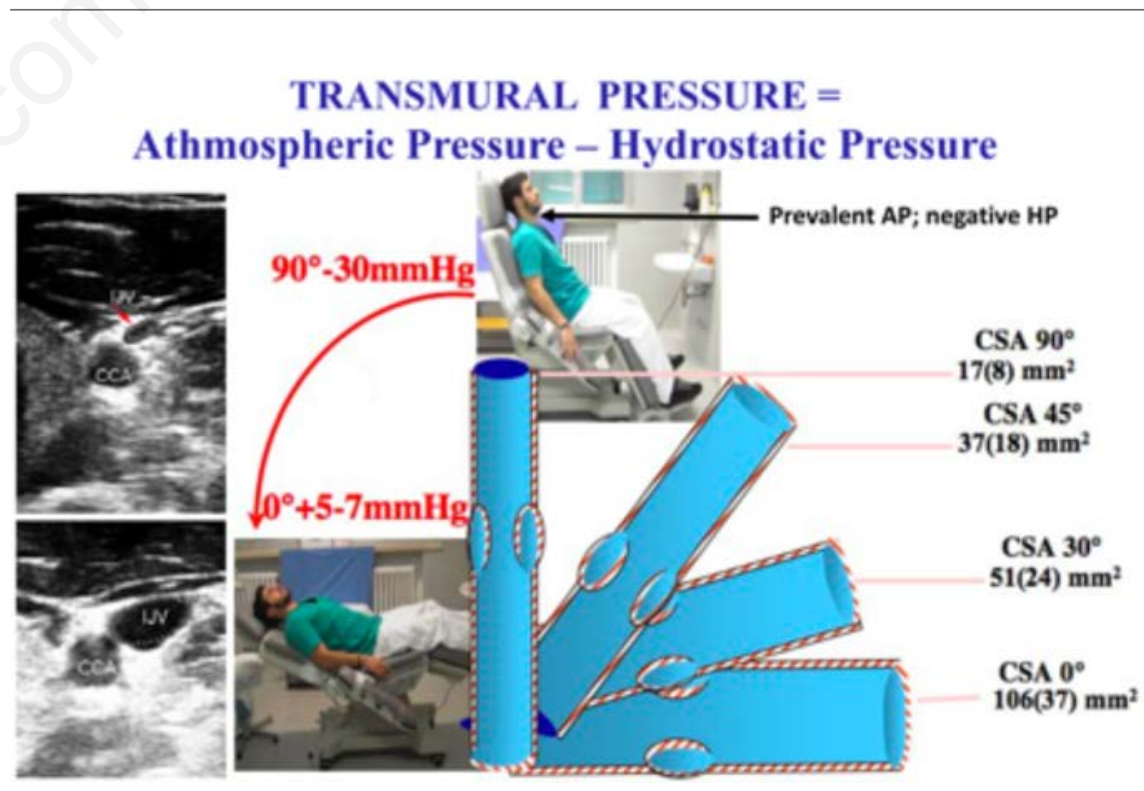

Figure 8. CSA variation changing the hydrostatic pressure with posture in the IJV. CSA is largest in supine, characterized by a positive value of hydrostatic pressure. Passing progressively in upright the pressure becomes negative, and the external component of the transmural pressure, represented by the atmospheric pressure, becomes prevalent and press the IJV wall. The prevalence of the external pressure over the internal one results in a significantly reduced CSA. Data are derived from reference 24 . 
volume change with posture, as well as of vein pulsatility in proximity of the heart is the needing of dedicated stents. The latter should be a compliant scaffold capable to permanently adapt their CSA to the variation of volume and wall circumference of the vein. The use of arterial stents into the venous system decreases dramatically the mechanical wall properties of the vein and the compliance is definitively compromised. In addition, the probability of migration increases the risk of significant complications.

Venous compliance is sometimes very complex due to arterial pulsation transmitted to the vein wall. There are clinical cases treatable by endovenous stenting, such as the aorto-mesenteric compass of the left renal vein, or the May-Turner syndrome. The former condition leads to pelvic congestion syndrome and to ovarian varicocele in female; the latter is secondary to a partial obstruction of the common iliac vein by an overlying common iliac artery with subsequent entrapment of the left common iliac vein. The prevalence of both cases was underestimated in the past, but they are currently easily identified and increasingly treated by the means of stenting. Finally, pulsatile veins such as the internal jugular vein and the outlet of the supra-hepatic veins into the inferior vena cava, can be affected by truncular venous malformation needing endovascular treatment. Figure 9 represents the big variability of the jugular CSA along a single cardiac cycle. The sequence of different measures of the CSA clearly indicates how is variable the caliber of a pulsatile vein in close proximity of the right atrium. Dedicated new stenting technologies are needed for a better flow and function restore in the diseased veins, which take into account the forgotten concept of venous compliance.

Moreover, the proposed ultrasonographic techniques to derive venous compliance in a clinical setting, by the means of common duplex and/or echocolorDoppler equipments permits to investigate, understand, and assess further clinical implication of venous compliance. Ultrasound methods assimilate the CSA to the volume of the vein, because, as stated above, it reflects the blood content. Changes in CSA can be reliably measured by ultrasound in response to a change in posture, while pressure can be derived from the hydrostatic pressure changes. ${ }^{17}$

Further clinical implications of venous compliance measurement are the followings: i) the interpretation of varicose veins as a C' epiphenomenon, in consequence of increased blood volume and pressure in the lower extremities; ${ }^{23}$ ii) the possibility of

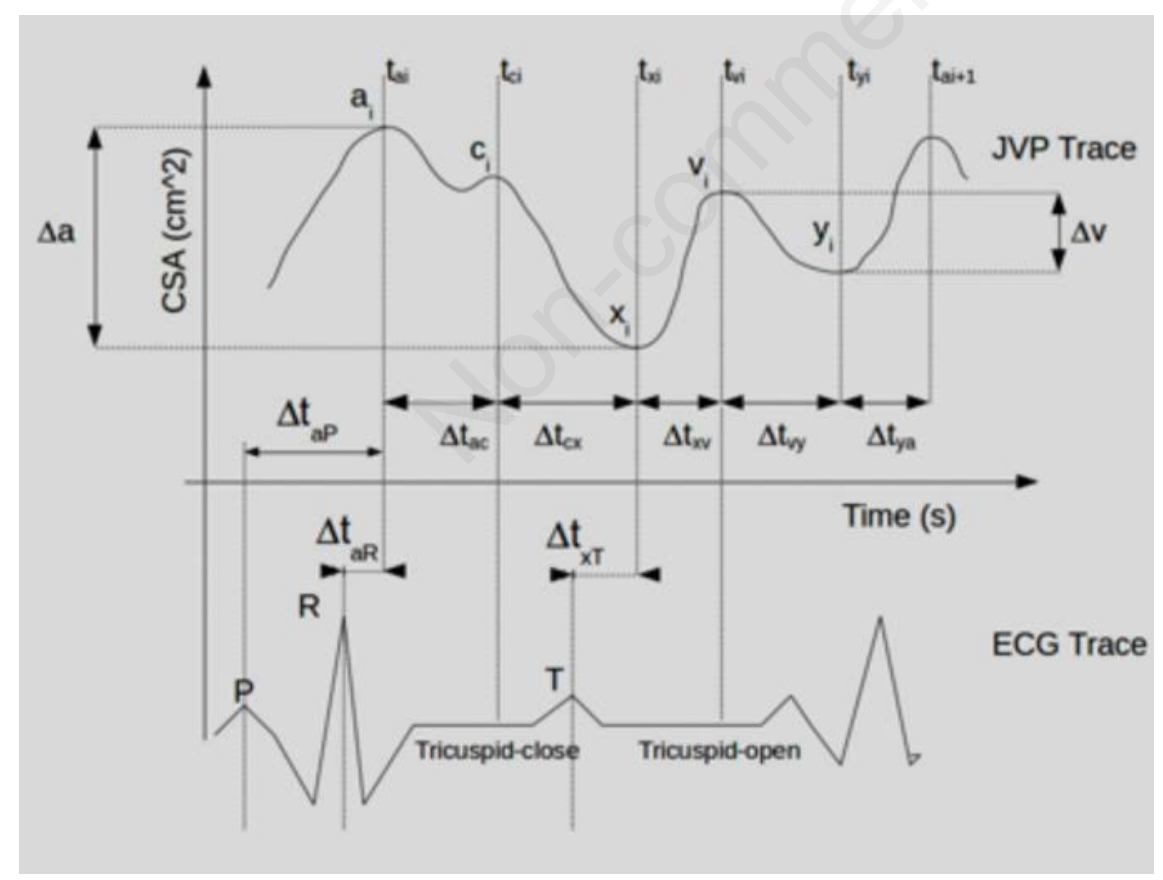

Figure 9. Upper part: The curve of the jugular venous pulse with respectively the a, $c, x$, $v, y$ peaks described in the text. The curve represents the CSA variations along a single cardiac cycle, compliant with the atrial pressure. Lower part: The jugular curve (JVP trace) is synchronized with a single heartbeat, in the interval between $2 \mathrm{R}$ waves of the ECG trace. The tricuspid closure corresponds to a positive $C$ wave in the JVP trace. To the contrary the tricuspid opening attires blood from the jugular creating the $y$ negative wave of emptying. ultrasonographyc assessment of ambulatory venous pressure. ${ }^{17}$ From this point of view, venous compliance may explain or predict us the reduction of varicose veins CSA following high ligation and/or suppression of reflux from the saphenous vein and an incompetent tributary. Practically, an ultrasonographic assessment of the Perthes test. It could be proposed to assess before surgery by applying a tourniquet in the lower limb the expected lowering of the ambulatory venous pressure. This is easy to do and should be particularly indicated before Muller, ASVAL, and CHIVA procedures; iii) the equivalence between measure of volume non-invasively assessed by the means of air plethysmography and/or water plethysmography and the invasive measurement of ambulatory venous pressure. ${ }^{13,39,40,41}$

\section{References}

1. Mashiah A, Rose SS, Hod I. The scanning electronic microscope in the pathology of varicose veins. Israel J Med Sci 1991;27:202-6.

2. John J. Bergan and Nisha Bunke Eds The Vein Book. New York: Oxford University Press; 2014.

3. Dhital KK, Burnstock G. Adrenergic and non adrenergic neural control of the arterial wall. In: Camilleri J-P, Berry CL, Fiessinger J-N, Bariety J, eds. Disease of the arterial wall. London: Springler-Verlag; 1989. pp 97-126.

4. Chen H, Angerer JI, Napoleone M, et al. Hematocrit and flow rate regulate the adhesion of platelets to von Willebrand factor. Biomicrofluidics 2013;7:64113.

5. André P, Denis CV, Ware J, et al. Platelets adhere to and translocate on von Willebrand factor presented by endothelium in stimulated veins. Blood 2000;96:3322-8.

6. Badimon L, Badimon JJ, Rand J, et al. Platelet deposition on von Willebrand factor-deficient vessels. Extracorporeal perfusion studies in swine with von Willebrand's disease using native and heparinized blood. J Lab Clin Med 1987;110:634-47.

7. Sanchez-Hanke M, Puschel K, Leuwer R. Anatomy of the valve system of the internal jugular vein. Laryngohinootologie 2000;79:332-6.

8. Zamboni P, Tisato V, Menegatti E, et al. Ultrastructure of internal jugular vein defective valves. Phlebology 2015;30:644-7.

9. Uhl JF, Gillot C. Anatomy of the venomuscular pumps of the lower limb. Phlebology 2015;30:180-93. 
10. Abbott WM, Megerman J, Hasson JE, et al. Effect of compliance mismatch on vascular graft patency. J Vasc Surg 1987;5:376-82.

11. Thulesius O. Vein wall characteristics and valvular function in chronic venous insufficiency. Phlebology 1993;8:94-8.

12. Thulesius O, Ugaily-Thulesius L, Gjores JE, Neglen P. The varicose saphenous vein, functional and ultrastructural studies, with special reference to smooth muscle. Phlebology 1988;3:89-95.

13. Norgren L, Thulesius O. Pressure-volume characteristics of foot veins in normal cases and patients with venous insufficiency. Blood Vessels 1975;12:112.

14. Folkow B, Neil E. Circulation. New York: Oxford University Press; 1973.

15. Baird RN, Kidson IG, L'talien GJ, Abbott WM. Dynamic compliance of arterial graft. Am J Physiol 1977;233:H568-72.

16. Cromer AH. Physics for the life sciences. New York: Mc Graw Hill; 1977. pp 136-45.

17. Zamboni P, Portaluppi F, Marcellino $\mathrm{MG}$, et al. Ultrasonographic assessment of ambulatory venous pressure in superficial venous incompetence. J Vasc Surg 1997;26:796-802.

18. Davies AH, Magee TR, Baird RN, et al. Vein compliance: a preoperative indicator of vein morphology and of veins at risk of vascular graft stenosis. Br J Surg 1992;79:1019-21.

19. Davies AH, Magee TR, Hayward J, et al. Non-invasive methods of measuring venous compliance. Phlebology 1992;7:78-81.

20. Kidson IG, Abbott WM. Low compliance and arterial graft occlusion. Circulation 1977;58:1-4.

21. Zamboni P, Marcellino MG, Portaluppi
$\mathrm{F}$, et al. The relationship between in vitro and in vivo venous compliance measurement. Int Angiology 1996;2:178.

22. Zamboni P, Marcellino MG, Quaglio D, et al. A reliable non invasive methods for venous compliance measurements. Phlebology 1995;10:277-9.

23. Zamboni P, Marcellino MG, Murgia AP, et al. The probability of lower compliance values in advanced varicose veins disease. Int Ang 1995;14:298-9.

24. Zamboni P, Portaluppi F, Marcellino $\mathrm{MG}$, et al. In vitro versus in vivo assessment of vein wall properties. Ann Vasc Surg 1998;12:324-9.

25. Baird RN, Abbott WM. Pulsatile blood flow in arterial graft. Lancet 1976;1976:948-50.

26. Pollack AA, Wood EH. Venous pressure in the saphenous vein at the ankle in man during exercise and changes in posture. J Appl Physiol 1949;1:649-62.

27. Folkow B, Neil E. Circulation. New York: Oxford University Press; 1973.

28. Ibegbuna V, Delis KT, Nicolaides AN, Aina O. Effect of elastic compression stockings venous hemodynamics during walking. J Vasc Surg 2003;37:420-5.

29. Valdueza JM, von Münster T, Hoffman $\mathrm{O}$, et al. Postural dependency of the cerebral venous outflow. Lancet 2000;355:200-1.

30. Milnor WR. Hemodynamics. Baltimore: Williams \& Wilkins; 1982.

31. Zamboni P, Menegatti E, Conforti P, et al. Assessment of cerebral venous return by a novel plethysmography method. J Vasc Surg 2012;56:67785.e1.

32. Gisolf J, van Lieshout JJ, van Heusden $\mathrm{K}$, et al. Human cerebral venous outflow pathway depends on posture and central venous pressure. J Physiol 2004;560:317-27.
33. Zamboni P, Sisini F, Menegatti E, et al. An ultrasound model to calculate the brain blood outflow through collateral vessels: a pilot study. BMC Neurol 2013;13:81.

34. Garg N, Garg N. Jugular venous pulse: an appraisal. J Indian Acad Clin Med 2000;1:260-9.

35. Chua Chiaco JMS, Parikh NI, Fergusson DJ. The jugular venous pressure revisited. Clev Clin J Med 2013;10:638-44.

36. Sisini F, Tessari M, Menegatti E, et al. Clinical applicability of the assessment of the jugular flow over the individual cardiac cycle compared with current ultrasound methodology. Ultrasound Med Biol 2016;42:1750-63.

37. Sisini F, Toro E, Gambaccini $M$, Zamboni P. The oscillating component of the internal jugular vein flow: the overlooked element of cerebral circulation. Behav Neurol 2015;2015:170756.

38. Caillard A, Gayat E, Tantot A, et al. Comparison of cardiac output measured by oesophageal Doppler ultrasonography or pulse pressure contour wave analysis. Br J Anaesth 2015;114:893900.

39. Christopoulos D, Nicolaides AN, Szendro G. Venous reflux: quantification and correlation with the clinical severity of chronic venous disease. $\mathrm{Br} \mathrm{J}$ Surg 1988;75:352-6.

40. Franceschi C. Who knows the rationale of the refilling time measured by plethysmography? Veins and Lymphatics 2018; 7:7199 doi:10.4081/vl.2018.7199

41. Tisato V, Zauli G, Voltan R, et al. Endothelial cells obtained from patients affected by chronic venous disease exhibit a pro-inflammatory phenotype. PLoS One 2012;7:e39543. 